\title{
Calculated Right Ventricular Ejection Fraction
}

National Cancer Institute

\section{Source}

National Cancer Institute. Calculated Right Ventricular Ejection Fraction. NCI Thesaurus. Code C135380.

The percent or fraction of the right ventricular end diastolic volume ejected in systole, which is calculated as the right ventricular stroke volume divided by the right ventricular end diastolic volume. 